\title{
Correlation of Obesity Status with Zinc Serum Levels and Insulin Resistance in Perimenopause Obese Women
}

\author{
Heidi Listya ${ }^{1}$, Muhammad Sulchan², Etisa Adi Murbawani ${ }^{2 *}$, Niken Puruhita², \\ Amalia Sukmadianti²
}

${ }^{1}$ Resident of Clinical Nutrition Department, Faculty of Medicine, Diponegoro University / Kariadi Hospital Semarang ${ }^{2}$ Staff of Clinical Nutrition Specialist Program, Faculty of Medicine, Diponegoro University/ RSUP dr. Kariadi, Indonesia

Keywords:

Insulin resistance

Obese women

Obesity status

Serum zinc levels

*) Correspondence to: etisatitis@gmail.com

Article history:

Received 29-11-2020

Accepted $04-12-2020$

Availableonline10-12-2020

\begin{abstract}
Background: Obesity is one of the global health problems. The prevalence of obesity in women is higher than men. Various metabolic problems are caused by obesity, such as insulin resistance and deficiency of micronutrients such as zinc. The occurrence of insulin resistance in obesity is also influenced by zinc deficiency

Objective: To analyse the correlation of obesity status with serum zinc levels and insulin resistance in perimenopause obese women.

Methods: Correlational research with 62 perimenopause obese women subject aged 40-50 years old who met the inclusion and exclusion criteria. Serum zinc levels were measurement using AAS and insulin resistance using HOMA IR formula. Serum zinc levels, fasting insulin, fasting blood glucose taken from venous blood. Hypothesis testing uses Pearson correlation

Results: $12.9 \%$ had low serum zinc levels and high HOMA IR 9.09\%. There was a significant negative correlation between BMI with serum zinc levels $(r=-0.402 ; p=$ $0.001)$ and significant positive correlation between BMI with insulin resistance ( $\mathrm{r}=$ 0.396; $\mathrm{p}=0.001$ ). There was a significant negative correlation between WC with serum zinc levels $(r=-0.18, p=0.161)$ and significant positive correlation between WC with insulin resistance $(\mathrm{r}=0.284, \mathrm{p}=0.025)$ and significant negative correlation between serum zinc levels with insulin resistance $(r=-0.404 ; p=0.001)$.

Conclusion: There is a correlation between obesity status with serum zinc levels and correlation between obesity status with insulin resistance in perimenopause obese women.
\end{abstract}

DIMJ, 2020, 1(2), 50-55 DOI: https:// doi.org/10.14710/dimj.v1i2.9559

\section{Introduction}

Obesity and excess body weight are global health problems as non-communicable diseases with an increasing tendency. Obesity is caused by excessive calorie intake, sedentary lifestyle, genetics, hormones and drugs. Obesity status is determined by body mass index (BMI), while central obesity or abdominal obesity is determined by body mass index (BMI), while central obesity or abdominal obesity is determined directly by waist circumference or waist circumference or waist to hip ratio (WHR), as well as indirectly by $\mathrm{BIA}^{1-5}$. The increased cardiovascular risk and mortality were higher due to central obesity as measured by $\mathrm{BMI}^{5}$. Various comorbid conditions are influenced by obesity status and are burdened as health problems of a country so that they affect health and socio-economic costs, so prevention is needed ${ }^{6}$.

The prevalence of obesity in women is higher than men ${ }^{7}$. Energy metabolism in women is dominated by fat storage in an active form that has not been metabolized so that it tends to increase the distribution of fat storage, as well as higher circulation of leptin and adiponectin and a higher percentage of Subcutaneous Adipose Tissue (SAT) ${ }^{8}$. Adipose tissue produces various hormones that affect body metabolism. 
Insulin resistance is a condition in which insulin is triggered to glucose uptake is disrupted in insulinsensitive tissues, namely in the muscles, liver and adipose tissue and inhibits the insulin signaling pathway $^{9,10}$. This mechanism is influenced by factors such as obesity, inflammation, oxidative stress, hypoxia, fatty liver, hyperinsulinemia, hyperlipidemia, aging, mitochondrial dysfunction, pregnancy, lipodystrophy, endoplasmic stress reticulum, and genetics apart from insulin resistance, there is also a micronutrient deficiency in obese individuals that affects physiological function, impaired immunity and increases the risk of comorbidity ${ }^{11}$. One of the deficiencies of micronutrient that occurs in obese individuals in zinc deficiency ${ }^{12}$.

Zinc is an essential trace mineral that plays a role in metabolism, growth and development, endocrine regulation, cytokine production, immune response, and growth of connective tissue, muscle and bone. The synthesis, storage and release of the hormone insulin into the pancreas is also assisted by zinc. Zinc deficiency is often found in obese people ${ }^{9,10}$. The interaction between Zinc Transporter * (ZnT8) which is dysfunction and decreasing plasma zinc concentration affects glucose tolerance ${ }^{3}$. Zinc affects glucose transport and increases peripheral insulin sensitivity, however there are only a few studies showing an association between serum zinc levels and insulin resistance ${ }^{13}$. Menopause is an aging process characterized by a transitional period of decreasing ovarian function and hormones ${ }^{14}$. One of the hormones that affects the perimenopause period is estrogen, which has a protective effect on insulin resistance. Estrogen levels in perimenopausal women decrease. Several studies have shown that serum estradiol levels have a negative correlation with HOMA-IR but have a positive correlation in postmenopausal women. Insulin resistance, impaired glucose metabolism and hyperinsulinemia are seen in men and women who are deficient in Estrogen Receptors (ER) and Cypq9 aromatase. 17- $\beta$-estradiol (E2) helps insulin work through insulin-sensitive tissues or indirectly with oxidative stress factors that trigger insulin resistance. In skeletal muscle, ER alpha has a positive effect on insulin signaling and the expression of Glucose Transporter 4 (GLUT 4), whereas ER beta is prodiabetogenic and reduces GLUT 4 expression. Based on the background described, the authors proposed the relationship between obesity status and serum zinc levels and RI in perimenopausal obese women to be studied.

\section{Method}

This research was a cross-sectional study that carried out in PKK sub district Meteseh, Sendangmulyo and Lempongsari in the Semarang city in healthy obese perimenopause women population aged 40-50 years old. Subjects are obese women ( $\mathrm{BMI} \geq 25$ ), aged $40-50$ years old, in menopause transition, can stand without the help of other people, no history or are suffering from DM type 2, no history or are suffering from cancer, no history or currently suffering from hypertension, not taking antipsychotic drugs (olanzapine, clozapine, risperidone, quetiapine, aripiprazole), not taking antidepressant drugs (tricylic, tetracyclic, MAOI, antiepileptic), bot taking hormonal drugs, steroid (rogestational, corticosteroid, hormonal contraceptives), not taking psychiatric and neurological drugs (ziprasidone, nortriptyline, nefazodone, fluvoxamine, sertraline, duloxetine, topiramate, zonisamide, lamotrigine) ${ }^{26}$, were included in the study.

Demographic data consist of age, address, education, occupation, historical past illness, menstrual period were taken using a questionnaire. The diagnosis of obesity in this study used BMI criteria from $\mathrm{WHO}$, and the risk factors for obesity were assessed by WC. The variables studied were: obesity status (BMI and WC), zinc serum levels, fasting blood glucose levels, fasting insulin levels and HOMA IR. The selection of research subjects was done by consecutive sampling that met the study inclusion criteria. Subjects were willing to take part in the study and sign the consent form.

Data analysis was performed with normality test (Kolmogorov - Smirnov test) and correlation test between the variables studied using Pearson correlation analysis ( $p$ value $<0.05, r$ value with $95 \%$ confidence interval). If the requirements are not met, then the Spearman correlation test is used. All data analysis was performed using a computer program, SPSS.

\section{Results}

This study was conducted on 80 subjects with 18 subjects are drop out because they did not match the inclusion criteria or did not participate in the blood test, with details of 3 subjects who did not come for sampling and 15 people dropped out because of high blood pressure on physical examination and also high fasting blood glucose levels. The total number of respondents who can meet the requirements for this study is 62 subjects. 
Table 1 Characteristics of Research Subject Data

\begin{tabular}{cccc}
\hline Parameter & $\mathrm{n}(\%)$ & Mean \pm SD & $\begin{array}{c}(\min - \\
\max )\end{array}$ \\
\hline $\begin{array}{c}\text { Age } \\
40-45 \text { y.o }\end{array}$ & $\begin{array}{c}25 \\
(40.32 \%)\end{array}$ & $46.19 \pm 2.87$ & $(40.00$ \\
$45-50$ y.o & 37 & & - \\
& $(59.68 \%)$ & $50.00)$ \\
Gender & & & \\
Woman & 62 & & \\
BMI $\left(\mathrm{kg} / \mathrm{m}^{2}\right)$ & $(100.00 \%)$ & & \\
Obesity I & 32 & $30.82 \pm 5.04$ & $(25.04$ \\
$(25-29.9)$ & $(51.61 \%)$ & & - \\
Obesity II & 30 & & $43.86)$ \\
$(\geq 30)$ & $(48.39 \%)$ & & \\
WC (cm) & & & \\
& 61 & $94.01 \pm 10.32$ & $(78.00$ \\
Woman $\geq 80$ & $(98.39 \%)$ & & - \\
Woman<80 & $(1.61 \%)$ & & $127.00)$ \\
\hline
\end{tabular}

$\mathrm{SD}=$ Standard Deviation

Table 1 showed most of the subjects (98.39\%) have waist circumference more than $80 \mathrm{~cm}$. The mean age of subjects was 46.19 years \pm 2.87 , while based on BMI, obesity type I was $51.61 \%$ and obesity type II was $48.39 \%$.

Table 2 Frequency Distribution of Research Variables

\begin{tabular}{lccc}
\hline Parameter & $\mathrm{n}(\%)$ & Mean \pm SD & $\begin{array}{c}(\mathrm{min}- \\
\mathrm{max})\end{array}$ \\
\hline \multicolumn{4}{c}{ Serum Zinc Levels $(\mu \mathrm{g} / \mathrm{dl})$} \\
$\quad$ Normal & 54 & $97.86 \pm$ & $(51.00$ \\
$70-150$ & $(87.10 \%)$ & 23.18 & - \\
Low & 8 & & $159.60)$ \\
$<70$ & $(12.90 \%)$ & & \\
Fasting Blood Glucose Levels $(\mathrm{mg} / \mathrm{dl})$ & \\
$\quad$ Normal & 50 & $91.21 \pm$ & $(68-$ \\
$<100$ & $(80.65 \%)$ & 12.45 & $125)$ \\
Prediabetes & 12 & & \\
$100-125$ & $(20.00 \%)$ & & \\
HOMA IR & & & \\
Low & 56 & $1.95 \pm 1.93$ & $(0.36-$ \\
$<2.2$ & $(90.32 \%)$ & & $11.52)$ \\
Normal & 1 & & \\
$2.2-2.5$ & $(1.61 \%)$ & & \\
High & 5 & & \\
$>2.5$ & $(8.06 \%)$ & &
\end{tabular}

Table 2 showed that that some respondents have normal serum zinc levels, $87.1 \%$, only $12.9 \%$ have low serum zinc levels. Normal fasting blood glucose levels were $80.65 \%, 20 \%$ has fasting blood glucose levels above normal.
Table 3 Bivariate Correlation Test Research Table

Variables of Status Serum Zinc Levels Obesity

\begin{tabular}{cll}
\hline & $\mathrm{r}$ & $\mathrm{p}$ \\
BMI & -0.402 & 0.001 \\
WC & -0.180 & 0.161 \\
\hline BI = Body Mass Index & & \\
WC = Waist Circumference & &
\end{tabular}

Table 3 showed that BMI had association with serum zinc levels with $\mathrm{p}$ value $<0.05$, WC did not have significant association with $\mathrm{p}>0.05$.

Table 4 showed that insulin resistance had significant correlation with serum zinc levels with $p$ value $<0.05$.

Table 4 Bivariate Correlation Test between serum zinc levels and insulin resistance

\begin{tabular}{lll}
\hline \multicolumn{1}{c}{ Variable } & \multicolumn{2}{c}{ Insulin Resistance } \\
\hline Serum zinc levels & $\mathrm{r}$ & $\mathrm{p}$ \\
& -0.404 & 0.001 \\
\hline correlation coefficient & &
\end{tabular}

\section{Discussion}

Zinc deficiency occurs in obese people. Research conducted on obese adults and obese children showed a significant reduction in serum zinc concentration ${ }^{3}$. The action of zinc on the pancreas is associated with zinc and insulin homeostasis because zinc is stored and secreted from the pancreas together with insulin, so if there is dysregulation of metabolism homeostasis, zinc in the pancreas hence glycemic control is also affected. Hyperglycemia and hyperinsulinemia associated with systemic blood glucose regulation are directly affected by zinc deficiency ${ }^{15,16}$.

Zinc plays a role in structural stability and insulin synthesis, in in-vitro studies of anti-diabetic potential and insulin mimetic zinc in experimental animals, found in-vitro in 1980 the formation of zinc chloride $\left(\mathrm{ZnCl}_{2}\right)$ is similar to insulin, then further research found zinc deficiency in experimental animals reduce insulin sensitivity and zinc is associated with insulin action ${ }^{17,18}$

Obesity is the main cause of insulin resistance through the ectopic accumulation mechanism of excessive adipocyte depots, as well as in liver and muscle cells due to excess energy uptake and reduced energy use ${ }^{19,20}$. The hypothesis that increased fat oxidation affects insulin resistance in obese states. Chronic inflammatory response is associated with obesity through cytokine production and activation of inflammatory signaling pathways. 
The development of insulin resistance related to the inflammatory response in two ways, firstly by activating inflammatory signals mediated by IRS-1 serine phosphorylation in sensitive cells such as myocytes and hepatocytes, secondly infiltration of inflammatory cells into adipose tissue, thereby altering adipocyte fat metabolism, cytokine production in adipose tissue ${ }^{19}$.

Insulin resistance is influenced by signal transduction defects in insulin action, namely ${ }^{21}$ : defects of insulin signaling cascade in IR/IRS-1 role, $\mathrm{PKC} \zeta / \lambda /$ PI 3-kinase pathway, defects of GLUT4 expression and function. ${ }^{22-24}$ Inhibitors of insulin signaling, inflammatory molecules and insulin resistance, changes in insulin receptors and role of IR/IGF-IR hybrid receptors.

Glucose homeostasis is the ability to regulate blood glucose within normal limits. How to measure HOMA-IR can be done by various methods, with direct and indirect. Fasting blood glucose level, Tolerance test oral glucose (TTOG), HbA1C can cause disruption of glucose homeostasis. ${ }^{25-27}$ HOMA was first used by Mathews et all in 1985, by calculating with equation ${ }^{28}$ :

HOMA1-IR $=($ PIP $x$ GDP $) / 22,5$

HOMA $1-\% \mathrm{~B}=(20 \mathrm{xPIP}) /(\mathrm{GDP}-3,5)$

In order to know insulin resistance and beta cell function, where the PIP is $\mathrm{mU} / \mathrm{l}, \mathrm{FBG} \mathrm{mmol} / \mathrm{l}$, if the unit of $\mathrm{FBG}$ is $\mathrm{mg} / \mathrm{dl}$ then the equation:

HOMA1-IR $=($ PIP x GDP $) / 405$

The results of correlation test showed a significant relationship between body mass index and serum zinc levels $(\mathrm{r}=-0.402, \mathrm{p}=0.001)$. A negative correlation coefficient means that body mass index is inversely related to serum zinc levels. The higher the body mass index, the lower the serum zinc level. Study conducted by Zaky et al showed that serum zinc levels in obese subjects had an inverse correlation with body mass index. Body mass index in the obesity category showed an inverse relationship with zinc due to zinc and leptin metabolism, as evidenced by studies in mice and in human serum leptin levels also decreased leptin secretion due to reduced zinc concentrations.

The correlation test results showed a significant correlation between waist circumference and zinc serum levels $(\mathrm{r}=-0.18, \mathrm{p}=0.161)$. The negative correlation coefficient means that waist circumference is inversely proportional to the serum zinc level, the higher the waist circumference, the lower the serum zinc level.

Research by Yerlikaya et al showed that waist circumference in obese subjects had an inverse correlation with serum zinc levels. An inverse correlation between zinc and BMI and waist circumference was also found in the study of Zohal et al. With the limit of waist circumference $\geq 102 \mathrm{~cm}$ for men and $\geq 88 \mathrm{~cm}$ for women. The results of this study is the higher the waist circumference, the lower the serum zinc level, this is in accordance with the theory of an increase in adipose tissue mass, activation of the inflammatory response and obesity due to changes in leptin levels due to deficiency of certain trace minerals, one of which plays a role in carbohydrate metabolism and insulin action.

The results of the correlation test showed a significant relationship between BMI and insulin resistance $(\mathrm{r}=0.396, \quad \mathrm{p}=0.001)$, weak positive correlation coefficient $(\mathrm{r}=0.396)$, meaning that $\mathrm{BMI}$ is directly proportional to insulin resistance, the higher the BMI, the higher the insulin resistance. Research conducted by Ozturk et al showed insulin as a significant predictor of BMI, while Okura et al showed BMI $\geq 23$ was a risk factor for insulin resistance and diabetes mellitus in Japan population.

The aging process is associated with insulin resistance, abdominal adiposity, decreased aerobic capacity due to reduced mass and function of heart and skeletal muscle cells and decreased vital capacity. Lifestyle with limited physical activity also plays a role in the aging process. Insulin mechanism is influenced by physical activity habit and prevents insulin resistance. Study conducted by Ravhette et all about body composition and waist circumference means for health risk assessment. Age, body composition and physical activity are also associated with body muscle mass and increased adiposity due to menopause in women and andropause in men. The results of correlation between BMI and insulin resistance in this study are in accordance with existing theories, and are supported by several studies conducted by Ozturk et al, Rachette et al and Zadeh et al.

The correlation test results between waist circumference and insulin resistance showed a significant relationship $(\mathrm{r}=0.284, \mathrm{p}=0.025)$. A positive correlation coefficient $(\mathrm{r}=0.284)$ means that waist circumference is directly proportional to insulin resistance. The higher the waist circumference, the higher the insulin resistance.

Obesity can be determined not only by measuring BMI, but also by measuring BMI, but also measuring waist circumference to describe the distribution of adiposity, in the abdominal area, which correlates with insulin resistance. The secretion of FFA and adipocytokines such as TNF- $\alpha$ and leptin from adipose tissue will interfere with the insulin signalling system and cause insulin resistance. The conclusion of study by Zadeh et al that waist circumference was directly related to insulin 
resistance and the cut-off value associated with insulin resistance was $88.5 \mathrm{~cm}$ for the reproductive age group in Iranian women.

The correlation test between serum zinc levels and insulin resistance showed a significant correlation $(\mathrm{r}=-0.404, \mathrm{p}=0.001)$. The negative correlation coefficient $(\mathrm{r}=-0.404)$ meaning that serum zinc levels are inversely related to insulin resistance, the lower the serum zinc levels, the higher the insulin resistance. Study by Ranasinghe showed that the results of zinc supplementation reduced insulin resistance levels, study by Nazem et al by giving zinc supplementation for 8 weeks also decreased insulin resistance. Zinc in regulatory, catalytic and biological structure; mechanisms as cofactors and coenzymes in the homeostasis mechanism also plays an important role in insulin as a transporter out of the cytosol to enter the lumen of the intracellular organelles or out of cells and cellular signalling. The mechanism of zinc mimetic insulin activity on glucose and fat has been investigated that direct zinc transfers to the molecule as a cellular second messenger in glucose homeostasis and regulation of insulin signal via modulation of tyrosine kinase insulin receptor activity.

\section{Conclusion}

From the results of the study it can be concluded that $12.9 \%$ have low serum zinc levels, $8.06 \%$ have high insulin resistance and $90.32 \%$ have low insulin resistance. The components of obesity status, namely body mass index and waist circumference, were associated with serum zinc levels and insulin resistance. Serum zinc levels with insulin resistance show an adequate association.

\section{Ethical Approval}

This study was approved by Ethical Study Committee Diponegoro University with Number 44/EC/KEPK/FK-UNDIP/IV/2020

\section{Conflicts of Interest}

There were no conflicts of interest in this study.

\section{Funding}

No specific funding was provided for this article

\section{Author Contributions}

Supervision, Prof. dr. Muhammad Sulchan, M.Sc, Sp.GK(K) DA(Nutr), dr. Etisa Adi Murbawani, M.Si, Sp.GK, dr. Niken Puruhita, M.Med.Sc,Sp.GK(K), and dr. Amalia Sukmadianti, Sp.GK .

\section{Acknowledgments}

This work was supported by Department of Clinical Nutrition, Faculty of Medicine, Diponegoro University / Kariadi Hospital Semarang.

\section{References}

1. Chen Y, Peng Q, Yang Y, et al. The prevalence and increasing trends of overweight, general obesity, and abdominal obesity among Chinese adults: a repeated cross-sectional study. BMC Public Health 2019; 19: 1293.

2. Hubbard VS. Defining overweight and obesity: what are the issues? The American Journal of Clinical Nutrition 2000; 72: 1067-1068.

3. Nuttall FQ. Body Mass Index: Obesity, BMI, and Health. Nutrition Today 2015; 50: 117128.

4. Müller MJ, Geisler C. Defining obesity as a disease. Eur J Clin Nutr 2017; 71: 12561258.

5. Heianza Y, Qi L. Genetics of Central Obesity and Body Fat. In: Nutrition in the Prevention and Treatment of Abdominal Obesity. Elsevier, pp. 153-174.

6. Jonathan Q Purnell, MD. Definitions, Classification, and Epidemiology of Obesity. Endotext Online, 2018.

7. Lumish HS, O'Reilly M, Reilly MP. Sex Differences in Genomic Drivers of Adipose Distribution and Related Cardiometabolic Disorders: Opportunities for Precision Medicine. ATVB 2020; 40: 45-60.

8. Pickett-Blakely O, Uwakwe L, Rashid F. Obesity in Women. Gastroenterology Clinics of North America 2016; 45: 317-331.

9. Hardy OT, Czech MP, Corvera S. What causes the insulin resistance underlying obesity?: Current Opinion in Endocrinology \& Diabetes and Obesity 2012; 19: 81-87.

10. Ye J. Mechanisms of insulin resistance in obesity. Front Med 2013; 7: 14-24.

11. Olechnowicz J, Tinkov A, Skalny A, et al. Zinc status is associated with inflammation, oxidative stress, lipid, and glucose metabolism. The Journal of Physiological Sciences 2018; 68: 19-31.

12. Mehdi Hedayati MRN, Ali Emami, Mojgan Asadi. Mutual Interaction between Obesity 
and Zinc Deficiency. J J Obesity 2016; 2: 16.

13. Rosalind S. Gibson. Principles of Nutritional Assessment. second edition. Oxford University Press.

14. Neelambikai. N PRaniN. To Study The Effect of The Body Mass Index and Waist Hip Ratio on Blood Pressure in Pre- and Post-Menopausal Women. Int J Med Res Health Sci 2013; 2: 593-596.

15. Chukwuma CI, Mashele SS, Eze KC, et al. A comprehensive review on zinc(II) complexes as anti-diabetic agents: The advances, scientific gaps and prospects. Pharmacological Research 2020; 155: 104744.

16. Adachi Y, Yoshida J, Kodera Y, et al. A new insulin-mimetic bis(allixinato)zinc(II) complex: structure?activity relationship of zinc(II) complexes. J Biol Inorg Chem 2004; 9: 885-893.

17. Vardatsikos G, Pandey NR, Srivastava AK. Insulino-mimetic and anti-diabetic effects of zinc. Journal of Inorganic Biochemistry 2013; 120: 8-17.

18. Ruz M, Carrasco F, Rojas $\mathrm{P}$, et al. Nutritional Effects of Zinc on Metabolic Syndrome and Type 2 Diabetes: Mechanisms and Main Findings in Human Studies. Biol Trace Elem Res 2019; 188: 177-188.

19. Savage DB, Petersen KF, Shulman GI. Mechanisms of Insulin Resistance in Humans and Possible Links With Inflammation. Hypertension 2005; 45: 828833.

20. Petersen KF, Shulman GI. Etiology of Insulin Resistance. The American Journal of Medicine 2006; 119: S10-S16.

21. Sesti G. Pathophysiology of insulin resistance. Best Practice \& Research
Clinical Endocrinology \& Metabolism 2006; 20: 665-679.

22. Tremblay F, Lavigne C, Jacques $\mathrm{H}$, et al. Defective Insulin-Induced GLUT4 Translocation in Skeletal Muscle of High Fat-Fed Rats Is Associated With Alterations in Both Akt/Protein Kinase B and Atypical Protein Kinase C ( / ) Activities. Diabetes 2001; 50: 1901-1910.

23. Garvey WT, Maianu L, Zhu JH, et al. Evidence for defects in the trafficking and translocation of GLUT4 glucose transporters in skeletal muscle as a cause of human insulin resistance. J Clin Invest 1998; 101: 2377-2386.

24. Favaretto F, Milan G, Collin GB, et al. GLUT4 Defects in Adipose Tissue Are Early Signs of Metabolic Alterations in Alms1GT/GT, a Mouse Model for Obesity and Insulin Resistance. PLOS ONE 2014; 9: e109540.

25. Perreault K, Lagacé J-C, Brochu M, et al. Association between fat free mass and glucose homeostasis: Common knowledge revisited. Ageing Research Reviews 2016; 28: 46-61.

26. Colak A, Diniz G. Impaired Glucose Tolerance, Obesity and Inflammatory Mediators. In: Chackrewarthy S (ed) Glucose Tolerance. InTech. Epub ahead of print 12 December 2012. DOI: $10.5772 / 52378$.

27. Fonseca ÉJN da C, Figueredo Neto JA de, Rocha TPO, et al. Metabolic Syndrome and Insulin Resistance by HOMA-IR in Menopause. International Journal of Cardiovascular Sciences. Epub ahead of print 2018. DOI: 10.5935/23594802.20180009.

Wallace TM, Levy JC, Matthews DR. Use and Abuse of HOMA Modeling. Diabetes Care 2004; 27: 1487-1495. 